\title{
Welding influence on fatigue properties of two automobile steels
}

\author{
Ruibin Gou*, Wenjiao Dan**, Weigang Zhang***, Fei Liu****, Tingting Huang****** \\ *Shanghai Jiao Tong University, Shanghai 200240 China; Anhui Science and Technology University, Anhui, 233100 \\ China, E-mail:grb106@163.com \\ **Shanghai Jiao Tong University, Shanghai 200240 China, E-mail: wjdan@sjtu.edu.cn \\ ***Shanghai Jiao Tong University, Shanghai 200240 China, E-mail: wgzhang@sjtu.edu.cn \\ ****Shanghai Jiao Tong University, Shanghai 200240 China, E-mail: liufei@126.com \\ *****Shanghai Jiao Tong University, Shanghai 200240 China, E-mail:952790138@qq.com \\ cross $^{\text {ref }}$ http://dx.doi.org/10.5755/j01.mech.22.4.16158
}

\section{Introduction}

H-type welded frame beams, the main load bearing structure of heavy vehicles, usually subjects to an dynamic cyclic load of alternating stress which is smaller than their static ultimate strength in service. These frame girders are, therefore, prone to fatigue failure because fatigue cracks begin to generate in the frame beam owing to the long term pulsing load acting on them. Unstable propagation of those cracks might eventually lead to a sudden and catastrophic damage of the frame girder. Moreover, the failure of the frame can cause a large number of economic losses. To understand the occurrence of fatigue failure, studying the fatigue failure characteristics and fatigue lives of heavy vehicle frame girders using high cycle fatigue $(\mathrm{HCF})$ tests is of great importance.

Many studies on the fatigue properties of metal materials under high cycle fatigue tests have been conducted by both domestic and foreign researchers [1-6]. The high cycle and ultra-high cycle fatigue properties of Q345 bridge steel were given in References [7-9] and the fatigue properties of frame beams subjected to cyclic bending were reported in References [10] and [11], respectively. However, there have been few studies on the HCF properties of the heavy vehicle frame girders of Q345 and QSTE700 steels.

In this work, Q345 and QSTE700 steels two common materials used for making $\mathrm{H}$-shaped frame beams were employed in high-cycle fatigue tests to study the fa- tigue characteristics of H-type automobile frame girders. The materials' F-N curves which predict their fatigue lives were obtained by using group method. Fracture locations were analyzed to determine the influence of welding on the $\mathrm{H}$-type frame parts by metallographic observations.

\section{Experimental}

\subsection{Materials}

Q345 and QSTE700 were all directly supplied by a large steelworks. The mechanical properties of the two materials are given in Table 1 .

Table 1

Mechanical properties of the two tested materials

\begin{tabular}{|l|c|c|c|}
\hline Material & Rel / MPa & $\mathrm{Rm} / \mathrm{MPa}$ & Elongation \\
\hline Q345 steel & 350 & 585 & $21 \%$ \\
\hline QSTE700 steel & 743 & 819 & $20 \%$ \\
\hline
\end{tabular}

\subsection{Specimens and equipment}

Each H-shaped beam sample was made up of the middle, upper, and bottom steel plates and these three plates were assembled by the welding process. The shape and dimensions of the specimens are presented in Fig. 1 and Table 2, respectively. Each specimen should be without any visible surface defects after welding. 15 pieces were prepared for each of the two materials.

Table 2

Dimensions (in mm) of H-type welded beam specimens

\begin{tabular}{|c|c|c|c|c|c|c|c|c|c|}
\hline Material & $L$ & $a$ & $S$ & $B 1$ & $B 2$ & $h$ & $t 1$ & $t 2$ & $t 3$ \\
\hline Q345 & 400 & 50 & 300 & 51.2 & 51.2 & 81.2 & 6 & 6 & 6 \\
\hline QSTE700 & 400 & 50 & 300 & 50.8 & 50.8 & 80.8 & 4 & 4 & 4 \\
\hline
\end{tabular}

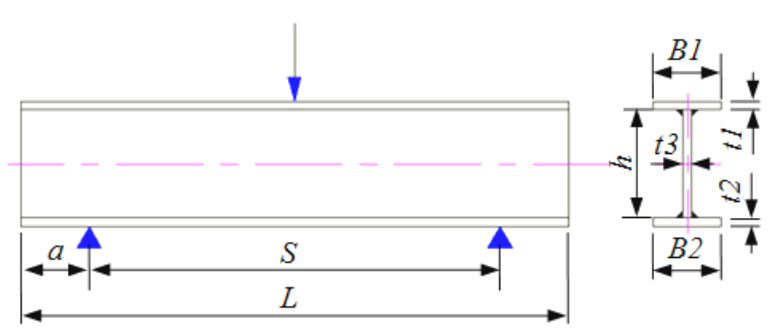

Fig. 1 H-type welded beam specimen

The test equipment includes a Chinese GPS300 high-frequency fatigue testing machine and a metallo- graphic microscope. The HCF machine has the maximum and minimum axial static output loads of 300 and $-300 \mathrm{kN}$, respectively. The maximum axial dynamic load was $150 \mathrm{kN}$, and its frequency varied from 80 to $250 \mathrm{~Hz}$.

\subsection{Welding parameters and requirements}

The welding process and parameters were the same as those used to produce frame beams in the large steelworks. Square groove and double side welding processes were adopted to enhance the strength in the welding zone of the girder specimen. The welding parameters in- 
clude: Current / 20A, Voltage / 220V, Weld speed / (350400) $\mathrm{mm} / \mathrm{min}$, Diameter of the ER50-6 welding wire / $1.2 \mathrm{~mm}$, Weld leg height / $6 \mathrm{~mm}$ for Q345 steel and $4 \mathrm{~mm}$ for QSTE700 steel.

The requirements of the welding process: (1) Angular distortion caused both by differential thermal expansion during the welding period and by non-uniform shrinkage after welding was controlled using a special auxiliary locating device which could firmly locate the middle, upper, and bottom plates throughout each welding period. (2) An optimum welding sequence and welding manner were designed to decrease the welding residual stress. Spot welding was first performed to locate those three plates before overall welding. (3) Shrinkages were considered and evaluated for dimensions $B 1, B 2$, and $h$ during the welding process and their values are $1.2 \mathrm{~mm}$ and $0.8 \mathrm{~mm}$ for Q345 and QSTE700 steels, respectively.

\subsection{Determination of fatigue load limit}

The fatigue load limit value defined as the load causing yielding in a local region in the part was calculated by finite element method under the three-point bending condition. The H-shaped beam shown in Fig. 1 was modeled by ABAQUS. The parameters of the beam were listed in Table 2, $B 1$ and $B 2$ were equal to $50 \mathrm{~mm}$ and $h$ was equal to $80 \mathrm{~mm}$. The element type was C3D8R. The load was performed on the centerline of the upper surface of the beam and two supports were symmetrically arranged on the bottom surface of the beam (Fig. 1), and the results were given in Fig. 2 whose $\mathrm{x}$-axis indicated the analysis time, and the whole analysis time was set to 1.0.

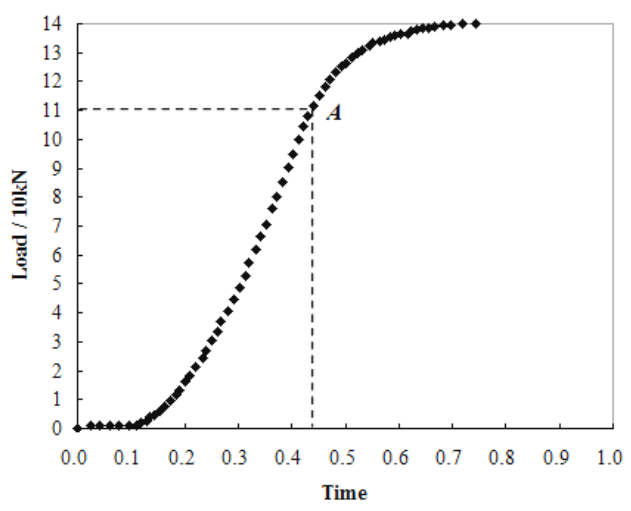

a

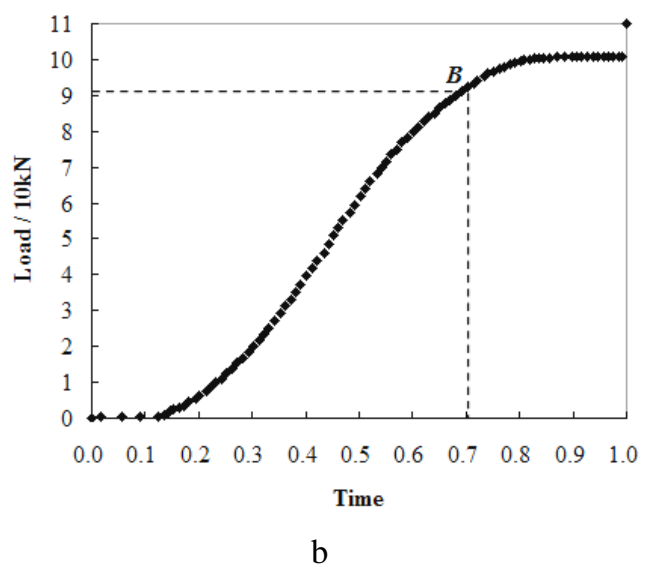

Fig. 2 The fatigue load limits of two steels by Finite element analysis. a - Q345 steel; b - QSTE700 steel
The fatigue load limit values would occur when the Von Mises stress reached $350 \mathrm{MPa}$ for Q345 steel and $700 \mathrm{MPa}$ for QSTE700 steel. The fatigue load limits were determined to be $110 \mathrm{kN}$ for Q345 steel and $90 \mathrm{kN}$ for QSTE700 steel, labeled point A in Fig. 2, a and point B in Fig. 2, b, respectively.

\subsection{Testing methods}

The testing methods include three-point bending in accordance with standard GB/T 232-2010 and the method of axial load control conforming to standard $\mathrm{GB} / \mathrm{T}$ 3075-2008.

We obtain the F-N curves of the two materials by group method in the HCF tests. Six stress levels were performed on each material and at least one specimen was tested at each stress level. In the fatigue test, the stress ratio, $\mathrm{R}$, was set to 0.1 for each of the stress levels.

The specimens were considered to be ineffective if one of the following occurred during the fatigue tests: (1) the frequency decreased by $5 \mathrm{~Hz}$; (2) the average or the alternating load decreased by $3 \mathrm{kN}$.

The fatigue life limits of the Q345 and QSTE700 welded samples were defined as the life with the lowest stress levels at which fatigue failure did not occur at $10^{7}$ cycles.

Metallographic of the base metal, the welding and the fatigue crack zones were observed to study the fracture characteristics. Failure analysis of each material was carried out by comparing the microstructure in these typical regions.

\section{Results and analysis}

For each material, fifteen samples divided into six groups were tested separately under six different stress levels. The stress level was gradually increased to the fatigue limit load from group 1 to group 6.

\subsection{HCF testing}

\subsubsection{Results and analysis for Q345 steel}

The six stress levels of the Q345 steel specimens were $60,70,80,90,100$, and $110 \mathrm{kN}$, respectively. The numbers of parts in each group were as follows: one piece for group 1, three pieces for groups 2, 4, 5 and 6, and two pieces for group 3. The results of the tests are given in Fig. 3.

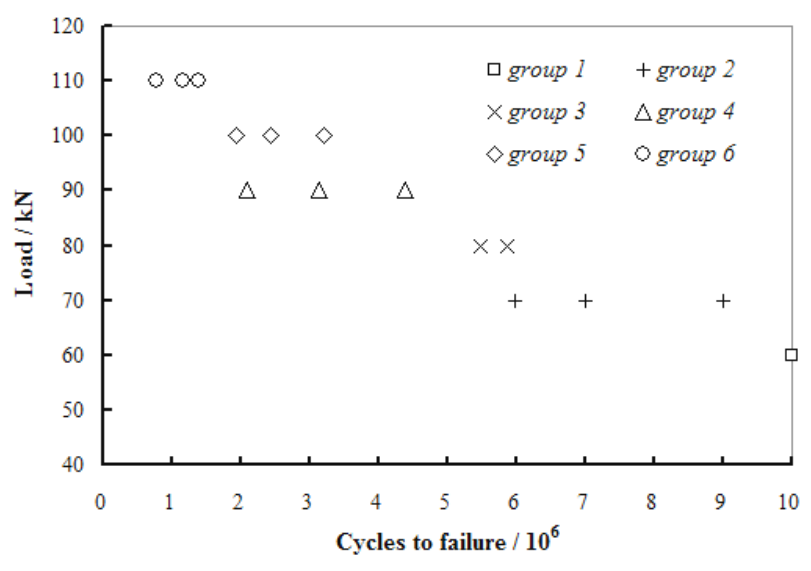

Fig. 3 Experimental F-N data for Q345 H-type specimens 
Both F-N curve (Fig. 4) and fitting formula Eq. (1) of the Q345 steel specimens were obtained based on the data in Fig. 3.

$$
\left\{\begin{array}{l}
\log F_{\max }=3.4418-0.2303 \log N ; \\
\gamma=-0.9247,
\end{array}\right.
$$

where $F_{\max }$ is the maximum fatigue load of each stress level; $N$ is the fatigue life when the survival rate was equal to $50 \%$, and $\gamma$ is the standard deviation.

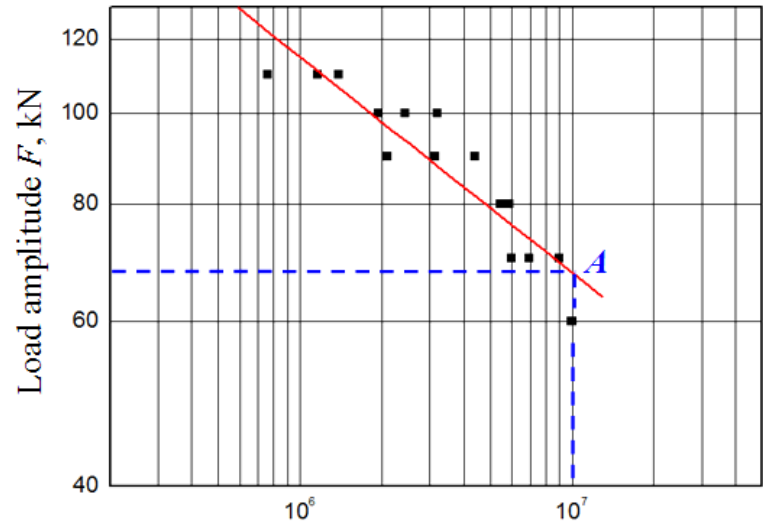

Cycles to failure, $N$

Fig. 4 Maximum fatigue load $(F)$ of each stress level versus the number of cycles to fatigue failure for $\mathrm{H}$ type Q345 steel specimens

Fig. 4 shows that the fatigue strength of the $6 \mathrm{~mm}$ H-type Q345 steel specimens was about $67.56 \mathrm{kN}$, located at point A marked by the two blue dashed lines on the fitting curve. The consistency of the data worsened with increasing the stress level.

\subsubsection{Results and analysis for QSTE700 steel}

The six stress levels of QSTE700 steel were 70, $75,78,80,85$, and $90 \mathrm{kN}$, respectively. Groups 1 to 3 and 6 all contained two samples, while groups 4 and 5 contained four and three samples, respectively. The results of the tests are given in Fig. 5.

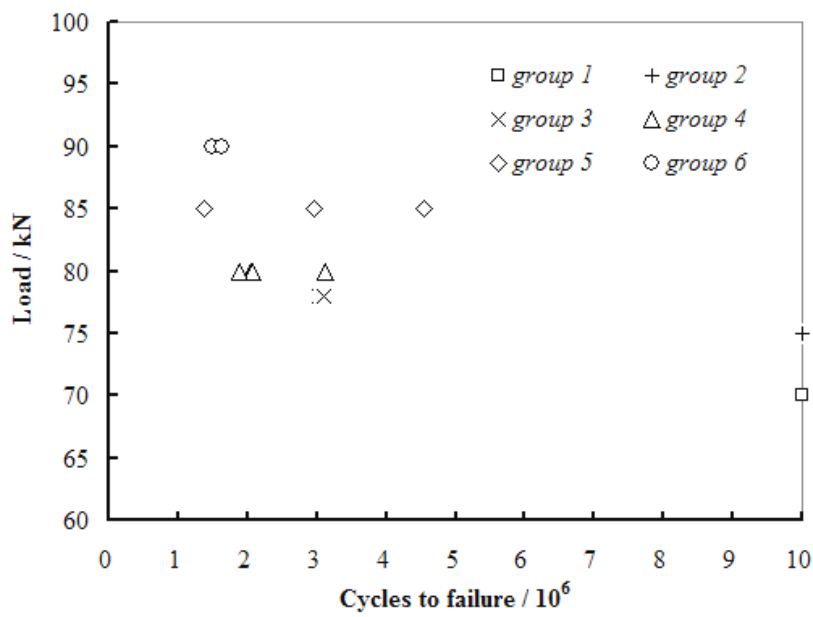

Fig. 5 Experimental F-N data for QSTE700 H-type specimens

Both F-N curve (Fig. 6) and fitting formula
Eq. (2) for the QSET700 steel specimens were obtained based on the data presented in Fig. 5 .

$$
\left\{\begin{array}{l}
\log F_{\max }=2.4562-0.0848 \log N \\
\gamma=-0.8104
\end{array}\right.
$$

where $F_{\max }$ is the maximum fatigue load for each stress level; $N$ is the fatigue life when the survival rate was equal to $50 \%$, and $\gamma$ is the standard deviation.

Fig. 6 indicates that the fatigue strength, the load at point $\mathrm{B}$ marked by the two blue dashed lines on the fitting curve, was about $72.88 \mathrm{kN}$ for the $4 \mathrm{~mm} \mathrm{H}$-type QSTE700 steel specimens. The data consistency was poorest at $85 \mathrm{kN}$.

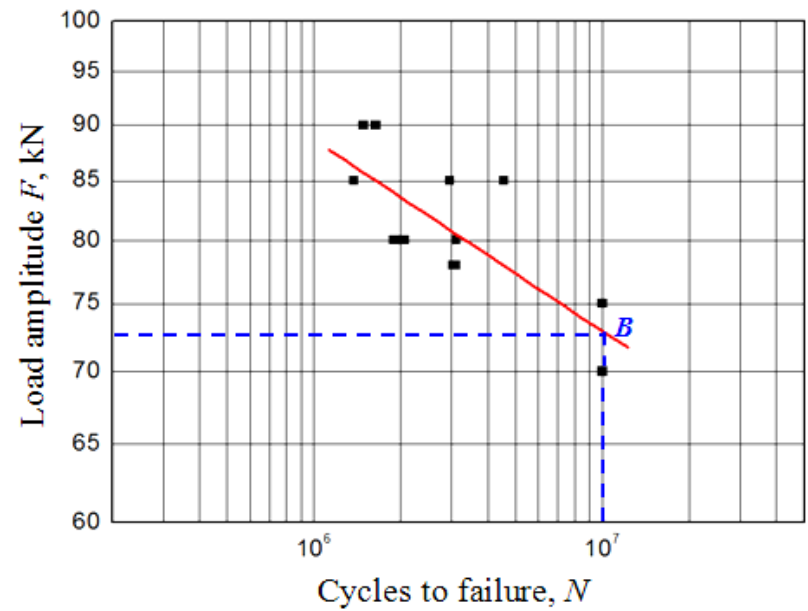

Fig. 6 the maximum fatigue load $(F)$ of each stress level versus the number of cycles to fatigue failure for $\mathrm{H}$ type QSTE700 steel specimens

\subsection{Fracture locations statistics and analysis}

Fatigue cracks in the samples were photographed after specimen fractured. The fracture locations of the two steels are represented in Fig. 7 and Fig. 8.

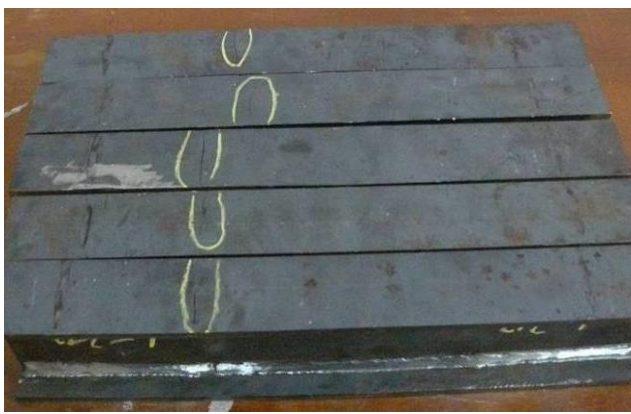

Fig. 7 Photographs of fractured Q345 steel samples

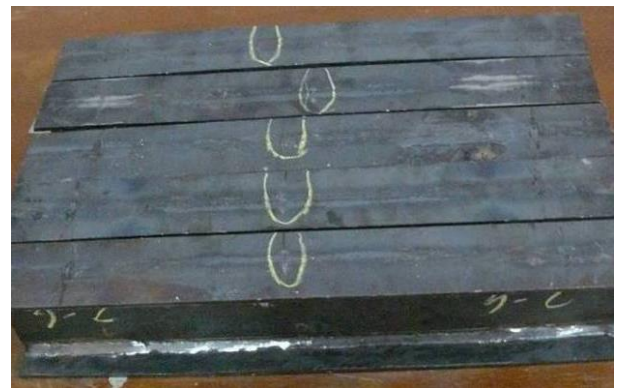

Fig. 8 Photographs of fractured QSTE700 steel samples 
From Fig. 7 and Fig. 8, it is clear that the failure locations in the Q345 steel parts were obviously different from those in the QSTE700 steel samples. The former fractured on the left side of the specimen center, but the latter fractured at the center of the specimen just below the loading line.

\subsection{Microstructural observations}

The metallography of base metal, welding and fracture zones was observed using a metallographic microscope to investigate the reasons for the observed fatigue fracturing. The images are given in Fig. 9 and Fig. 10.

For the Q345 steel samples, fatigue failure occurred in the repair welding zone. The main reason includes: (1) During the repair welding process, high welding residual stresses were generated, the grain size increased [12] and the number of impurity in the repair welding zone (Fig. 9, c) was much greater than that in the initial welding region (Fig. 9, b). (2) Because the strength of the base metal was smaller than that of welding zone, the influence of the weld nugget on the properties of the material was obvious and the consistency of each specimen became worse with increasing the weld nugget number which greatly enlarged the failure rate in the corresponding region during the fatigue test. Fig. 9, c exhibits that the number of weld nuggets in the repaired welding zone was greater than that in the initial welding zone.

In contrast to the Q345 steel parts, the yield strength of the QSTE700 base metal was larger than that of the welding zone, and therefore the influence of the weld nugget number on the material properties was slight. The material properties of the QSTE700 specimens were determined by the base metal properties without over-burning, and the failure location was expected to occur in the region where the tensile deformation was the largest. This is why the fracture always occurred in the initial welding zone (Fig. 10, c) directly under the location of loading, but not in the repaired welding zone (Fig. 10, b).

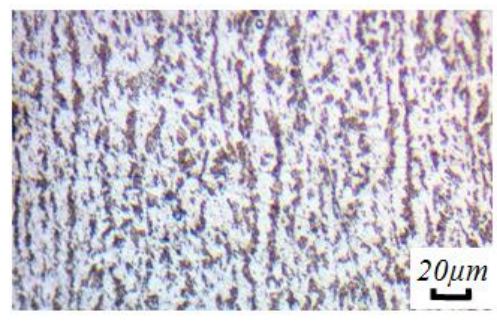

a

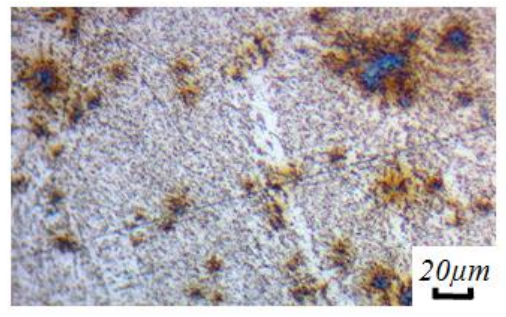

b

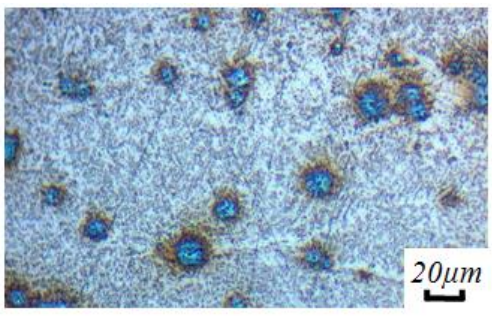

c

Fig. 9 Microstructure of typical zones in Q345 steel samples. a - Base metal zone; b - initial welding zone; c - repaired welding zone where fatigue cracks usually occurred

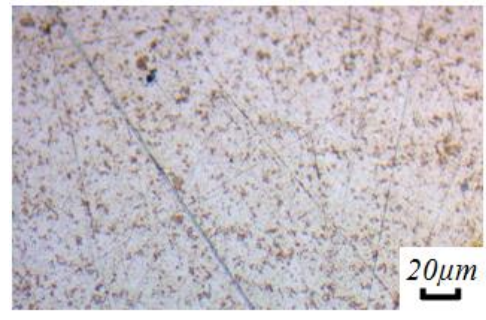

a

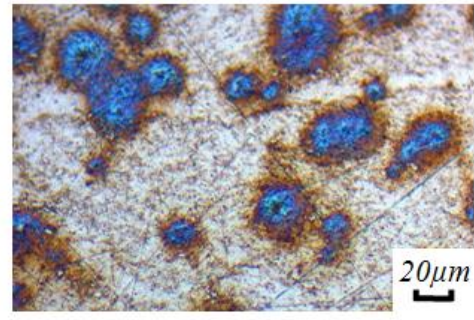

b

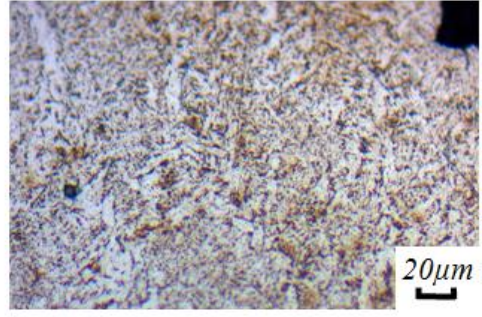

C

Fig. 10 Microstructure of typical zones on QEST700 steel samples. a-Base metal zone; b-repaired welding zone; $\mathrm{c}$ - initial welding zone where fatigue failure generally occurred

\section{Comprehensive analysis}

Based on Fig. 3 and Fig. 5, Eqs. (1) and (2), The

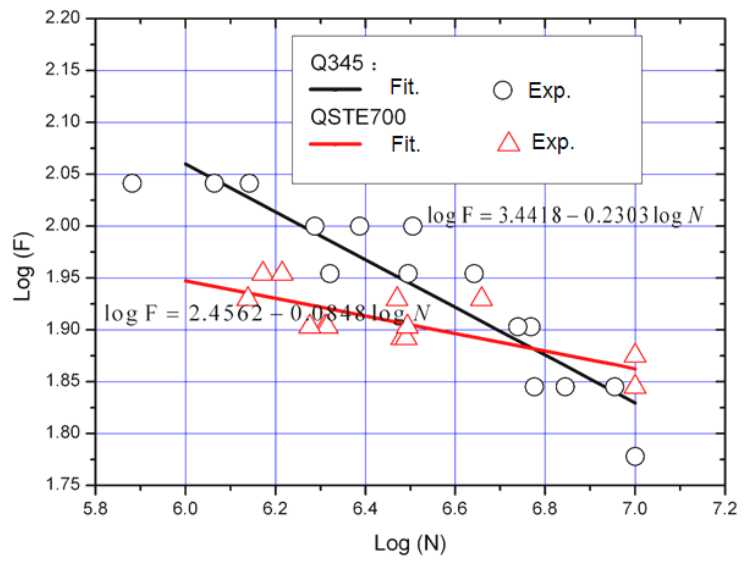

a
F-N results of the two materials are directly compared in Fig. 11, a while Fig. 11, b depicts their fatigue strengths at the same fatigue life.

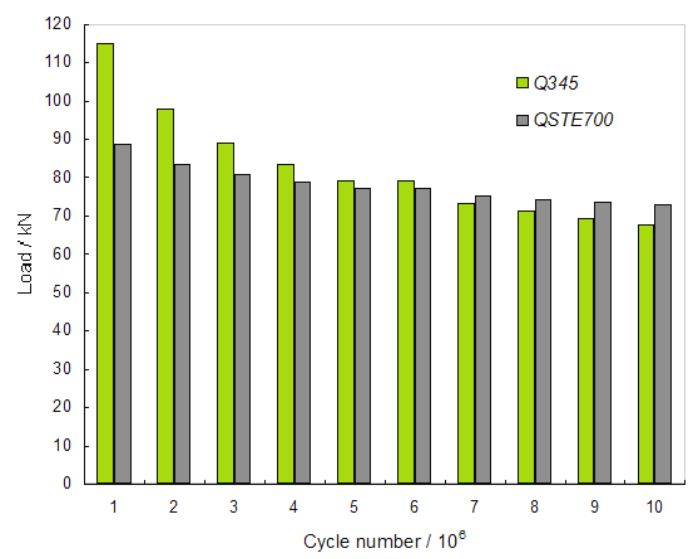

b

Fig. 11 Results of Q345 and QSTE700 steels $a$ - F-N curves; $b$ - histogram of fatigue strength 
In Fig. 11, the experimental data of the Q345 samples were scattered by comparing with that of the QSTE700 samples. The fatigue strength of Q345 steel was much higher than that of QSTE700 steel when the stress level was larger than $75 \mathrm{kN}$, but the fatigue strength was smaller than that of QSTE700 steel below $75 \mathrm{kN}$. The fatigue strength decreased by $41 \%$ for Q345 steel and $18 \%$ for QSTE700 steel, respectively, when the cycle number was between $10^{6}$ and $10^{7}$ cycles. These results indicate that the influence of the welding on Q345 steel was more obvious, which is in agreement with the fracture characteristics of the two materials as discussed in part 3.3. The fatigue strengths of the materials were $67.56 \mathrm{kN}$ for Q345 steel and $72.88 \mathrm{kN}$ for QSTE700 steel at the limit of cycle number, $10^{7}$ cycles.

\section{Conclusions}

Fatigue life prediction curves for H-type welded automobile frame girders were established by HCF test for both Q345 and QSTE700 steels shown in Eqs. (1) and (2). The anti-fatigue performance of Q345 steel was better than that of QSTE700 steel at $80 \mathrm{kN}$ and above, but worse than QSTE700 steel below $80 \mathrm{kN}$. The fatigue strengths of the two steels at $10^{7}$ cycles were $67.56 \mathrm{kN}$ and $72.88 \mathrm{kN}$, respectively.

The different H-type beam specimens exhibited different fracture locations. Those Q345 steel parts mainly cracked in the repaired welding regions in which contained more welding inclusions. Those QSTE700 steel samples fractured at the center of the specimen where the maximum tensile deformation occurred. The influence of welding, especially repair welding, is more serious for Q345 steel which accounts for the poor consistency of the experimental data.

\section{Acknowledgements}

This work was supported by the National Natural Science Foundation of China (Grant Nos. 51275296 and $51375307)$ and was supported by the Key Discipline Team (AKZDXK2015C03).

\section{References}

1. Zhang, Y.L.; Gou, R.B.; Li, J.M. et al.. 2012. Characteristics of metal magnetic memory signals of different steels in high cycle fatigue tests, Fatigue Fracture Engineering Materials Structures 35(7): 595-605. http://dx.doi.org/10.1111/j.1460-2695.2012.01651.x.

2. Das, H.; Chakraborty, D.; and Kumar Pal, T. 2014. High-cycle fatigue behavior of friction stir butt welded 6061 aluminium alloy, Transactions of Nonferrous Metals Society of China 24(3): 648-656. http://dx.doi.org/10.1016/S1003-6326(14)63107-1.

3. Haidemenopoulos, G.N.; Kermanidis, A.T.; Malliaros, C. et al. 2013. On the effect of austenite stability on high cycle fatigue of TRIP 700 steel, Materials Science \& Engineering A 573: 7-11. http://dx.doi.org/10.1016/j.msea.2013.02.015.

4. Yao, J.; Qu, X.H.; He, X.B. et al. 2012. Effect of inclusion on high cycle fatigue response of a powder metallurgy tool steel, Journal of Central South University 19(7): 1773-1779. http://dx.doi.org/10.1007/s11771-012-1206-z.

5. Jin, L.L.; Deng, C.Y.; Wang, D.P.; et al. 2011. Research on ultra-high cycle fatigue property of 45 steel, Advanced Materials Research 295-297: 1911-1914. http://dx.doi.org/10.4028/www.scientific.net/AMR.295 $-297.1911$

6. Khatibi, G.; Horky, J.; Weiss, B. et al. 2010. High cycle fatigue behaviour of copper deformed by high pressure torsion, International Journal of Fatigue 32(2): 269-278. http://dx.doi.org/10.1016/j.ijfatigue.2009.06.017.

7. He, C.; Liu, Y. and Wang, Q. 2013. Very high cycle fatigue properties of welded joints under high frequency loading, Advanced Materials Research 647: 817-821. http://dx.doi.org/10.4028/www.scientific.net/AMR.647 .817 .

8. Fang, D.H. et al. 2011. Ultra-high cycle fatigue behaviors of Q345 bridge steel welded joint', Transactions of the China Welding Institution 32(8): 77-80,117.

9. Zhao, X. 2012. Very long life fatigue behavior of Q345 bridge steel, Applied Mechanics and Materials 217219: 407-410

http://dx.doi.org/10.4028/www.scientific.net/AMM.217 $-219.407$.

10. Mashiri, F.R.; Zhao, X.L. 2010. Fatigue tests and design of welded thin-walled RHS-RHS and RHSangle cross-beam connections under cyclic bending, Thin-Walled Structures 48(2): 159-168. http://dx.doi.org/10.1016/j.tws.2009.07.006.

11. Mashiri, F.R.; Zhao, X.L.; Tong, L.W. 2013. Fatigue tests and design of welded thin-walled RHS-Channel and Channel-Channel cross-beam connections under cyclic bending', Thin-Walled Structures 63: 27-36. http://dx.doi.org/10.1016/j.tws.2012.09.002.

12. Tian, Z.L.; He, C.H.; Zhang, X.M. et al. 2001. Welding of 400Mpa Ultra fine Grain Steels', Transactions of the China Welding Institution 22(6): 1-3.

Ruibin Gou, Wenjiao Dan, Weigang Zhang, Fei Liu, Tingting Huang

\section{WELDING INFLUENCE ON FATIGUE PROPERTIES OF TWO AUTOMOBILE STEELS}

S u m m a r y

30 H-shaped welded beam specimens of Q345 and QSTE700 steels were tested in high cycle fatigue tests. Methods of finite element analysis, group method and microstructure observation were employed to investigate the fatigue properties of two kind of materials mentioned above in this work. The results show that the H-type welded specimens of different materials varied obviously in both their fatigue strengths and initial cracking locations. The fracture related to the relationship between the yield strength of the base metal and that of the welding zone. Welding, especially repair welding, has a apparent influence on the fatigue characteristics of Q345 steel.

Keywords: Fatigue performance, automobile frame girder, life evaluation, Q345 and QSTE700 steels.

Received September 15, 2015 Accepted July 4, 2016 